\title{
Taste-Guided Isolation of Bitter Lignans from Quercus petraea and Identification in Wine
}

\author{
Lauriane Sindt, ${ }^{\dagger+}$ Marine Gammacurta, ${ }^{\dagger+}$ Pierre Waffo-Teguo, ${ }^{\dagger \dagger}$ Denis Dubourdieu ${ }^{\dagger \dagger}$ \\ and Axel Marchal ${ }^{\dagger+*}$
}

† Univ. de Bordeaux, ISVV, EA 4577, Unité de recherche OENOLOGIE, 210 chemin de Leysotte, CS 50008, 33882 Villenave d'Ornon, France

*INRA, ISVV, USC 1366 OENOLOGIE, 210 chemin de Leysotte, CS 5000833882 Villenave d'Ornon, France 


\section{SUPPORTING INFORMATION}

Table S1. Gustatogram of CPC Fractions from the Q. petraea Wood Butanol Extract

Table S2. Gustatogram of semi-preparative HPLC Fractions Obtained from CPC VI Fraction.

S1. Negative LC-HRMS full scan chromatogram of p-HPLC fraction F

S2. HRMS spectra of the new compounds 1 (top) and 2 (bottom)

S3. HCD-HRMS spectra of the new compounds 1 (top) and $\mathbf{2}$ (bottom)

S4. ${ }^{1} \mathrm{H}$ NMR (600MHz, $\left.\mathrm{CD}_{3} \mathrm{OD}\right)$ spectra of the new compounds $\mathbf{1}$ (top) and 2 (bottom)

S5. 2D COSY $\left(\mathrm{CD}_{3} \mathrm{OD}\right),{ }^{1} \mathrm{H}(600 \mathrm{MHz})$ spectra of the new compounds $\mathbf{1}$ (top) and $\mathbf{2}$ (bottom)

S6. 2D ROESY (CD $3 \mathrm{OD}),{ }^{1} \mathrm{H}(600 \mathrm{MHz})$ spectra of the new compounds $\mathbf{1}$ (top) and $\mathbf{2}$ (bottom)

S7. 2D HSQC $\left(\mathrm{CD}_{3} \mathrm{OD}\right),{ }^{1} \mathrm{H}(600 \mathrm{MHz})$ and ${ }^{13} \mathrm{C}(150 \mathrm{MHz})$, spectra of the new compounds $\mathbf{1}$ (top) and 2 (bottom)

S8. 2D HMBC $\left(\mathrm{CD}_{3} \mathrm{OD}\right),{ }^{1} \mathrm{H}(600 \mathrm{MHz})$ and ${ }^{13} \mathrm{C}(150 \mathrm{MHz})$, spectra of the new compounds 1 (top) and 2 (bottom) 
Table S1.

\begin{tabular}{|c|c|c|c|c|}
\hline $\mathrm{CPC}$ fraction & tubes & mass (mg) & sensory description $^{a}$ & scale of bitterness \\
\hline $\mathrm{I}$ & $16-26$ & 200.0 & $\mathrm{x}$ & \\
\hline II & $27-35$ & 225.3 & bitter & $2 / 5$ \\
\hline III & $36-45$ & 240.5 & burning & \\
\hline IV & $46-51$ & 139.6 & bitter & $1 / 5$ \\
\hline $\mathrm{V}$ & $52-63$ & 257.5 & bitter & $2 / 5$ \\
\hline VI & $64-85$ & 441.0 & bitter & $4 / 5$ \\
\hline VII & $86-91$ & 118.0 & fresh & \\
\hline VIII & $92-104$ & 233.7 & sweet & \\
\hline IX & $105-112$ & 130.2 & burning & \\
\hline $\mathrm{X}$ & $113-119$ & 107.3 & sweet & \\
\hline XI & $120-134$ & 285.1 & sweet & \\
\hline XII & $135-155$ & 417.6 & sweet & \\
\hline XIII & $156-163$ & 1105.8 & $\mathrm{x}$ & \\
\hline XIV & $164-169$ & 2616.4 & $\mathrm{x}$ & \\
\hline XV & $170-190$ & 37.9 & $\mathrm{x}$ & \\
\hline
\end{tabular}

$a \mathrm{x}$ " indicates no difference was perceived between the supplemented solution and the non| supplemented one. 
Table S2.

\begin{tabular}{cccc}
\hline fraction & $\begin{array}{c}\text { mass } \\
(\mathrm{mg})\end{array}$ & $\begin{array}{c}\text { sensory } \\
\text { description }^{a}\end{array}$ & $\begin{array}{c}\text { scale of } \\
\text { bitterness }\end{array}$ \\
\hline A & 37.8 & bitter & $1 / 5$ \\
B & 27.0 & bitter & $4 / 5$ \\
C & 30.0 & $\mathrm{x}$ & \\
D & 24.5 & bitter & $1 / 5$ \\
E & 33.5 & sweet & \\
F & 44.7 & bitter & $3 / 5$ \\
G & 14.0 & bitter & $2 / 5$ \\
H & 56.2 & $\mathrm{x}$ & \\
I & 8.0 & $\mathrm{x}$ & \\
J & 65.0 & $\mathrm{x}$ \\
$a_{\text {"x" indicates no difference was perceived between the supplemented solution and the non- }}$ \\
supplemented one.
\end{tabular}


S1. Negative LC-HRMS full scan chromatogram of p-HPLC fraction F

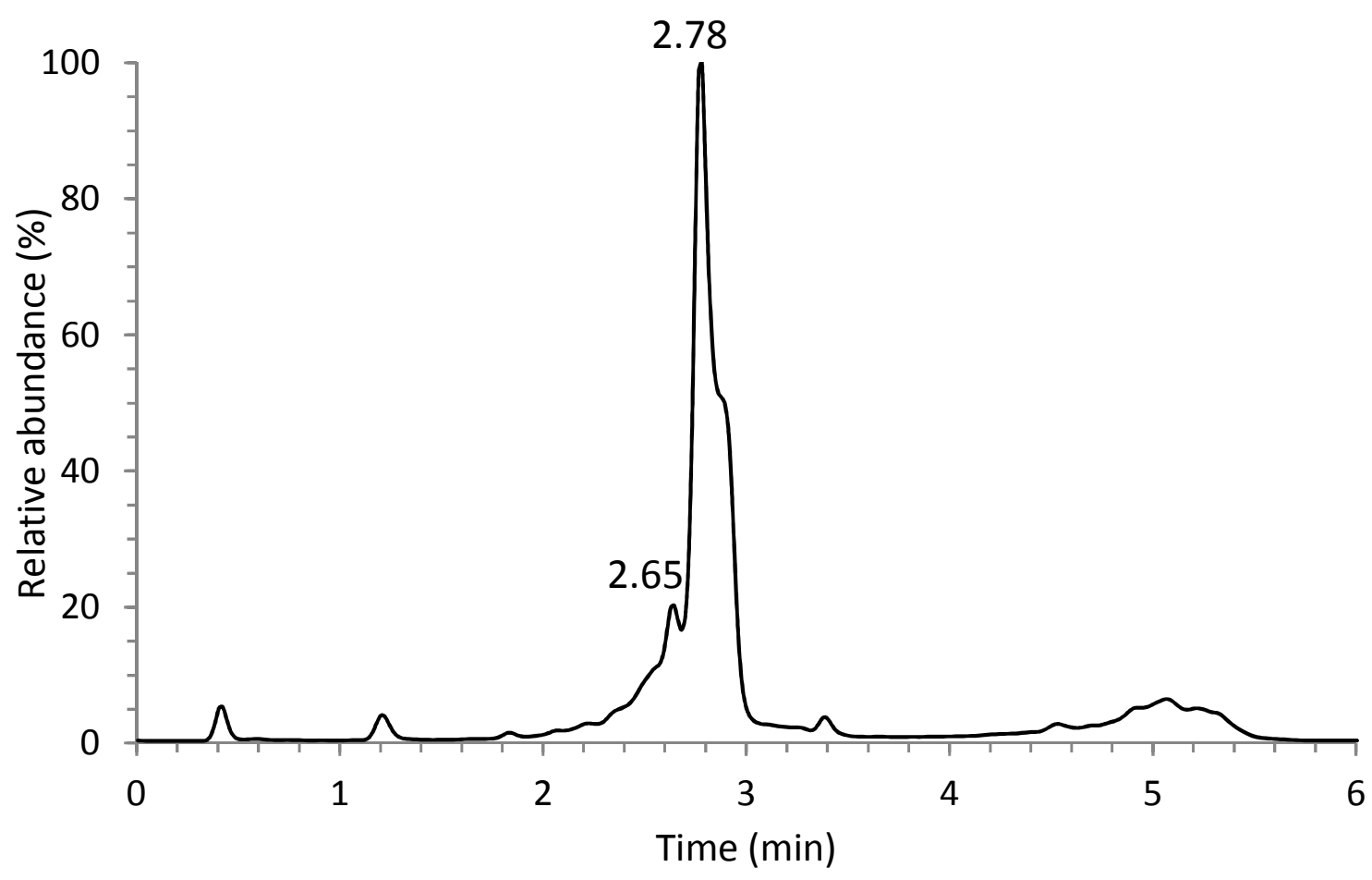


S2. HRMS spectra of the new compounds 1 (top) and 2 (bottom)

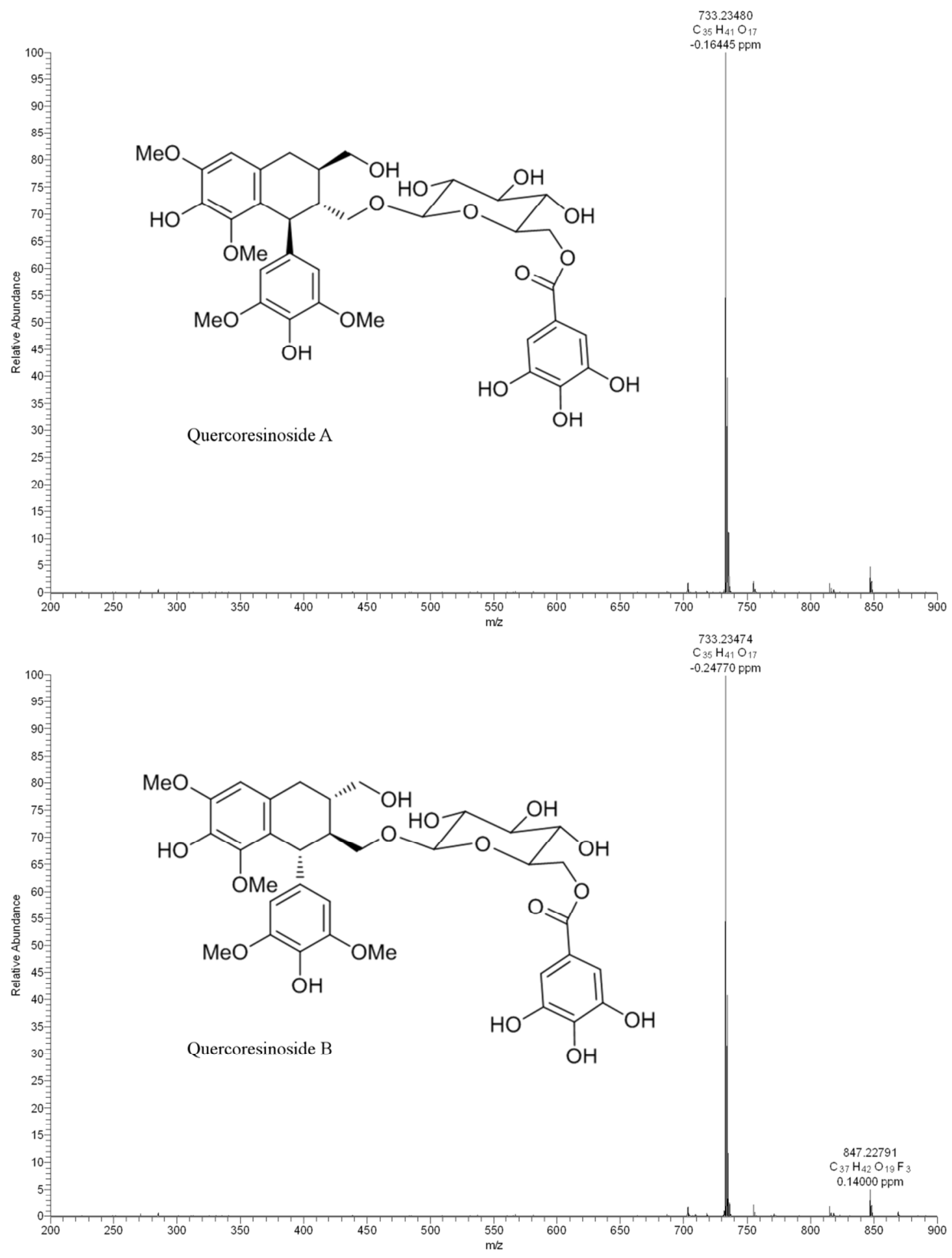


S3. HCD-HRMS spectra of the new compounds 1 (top) and 2 (bottom)
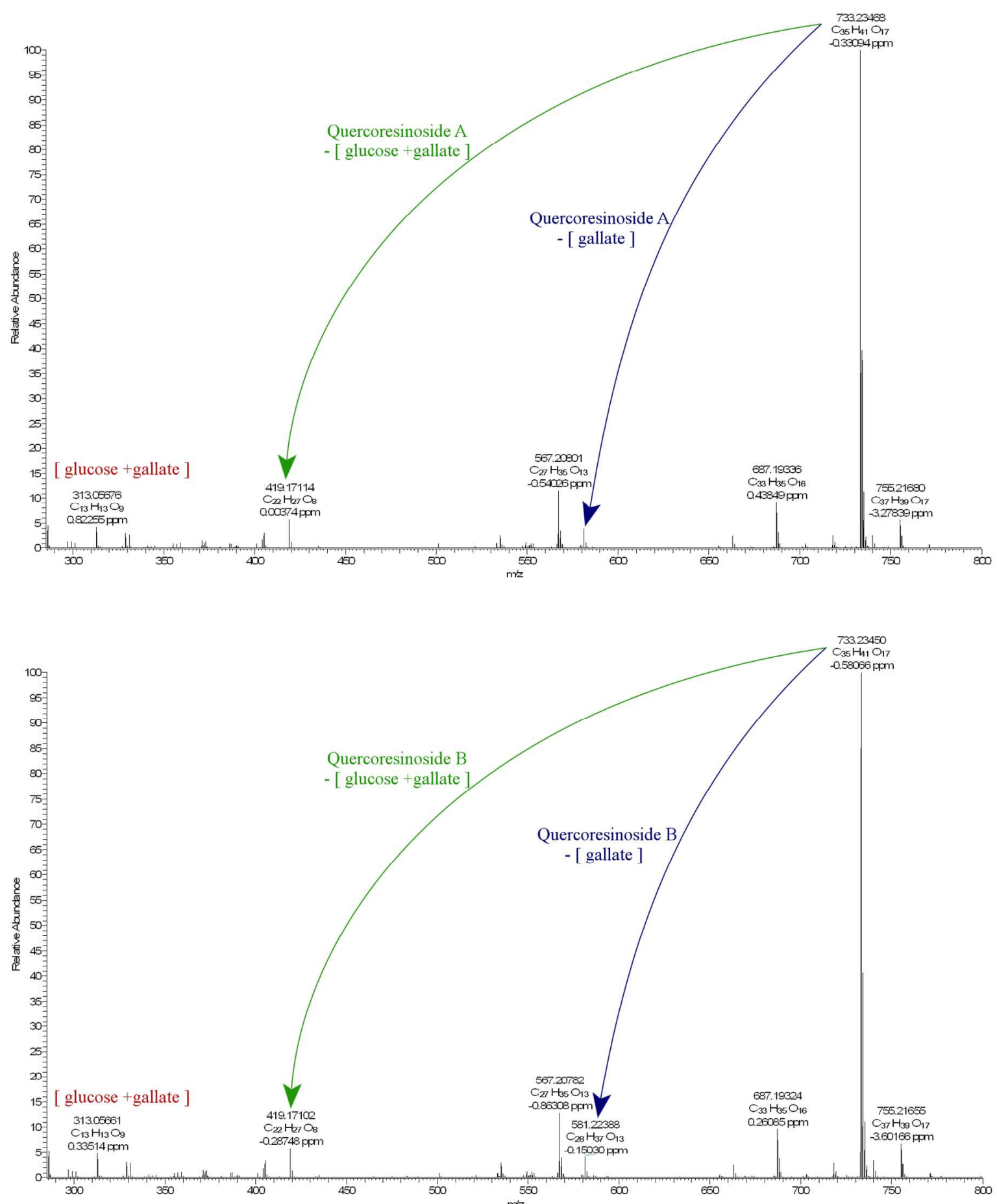
S4. ${ }^{1} \mathrm{H}$ NMR $\left(600 \mathrm{MHz}, \mathrm{CD}_{3} \mathrm{OD}\right)$ spectra of the new compounds 1 (top) and 2 (bottom)

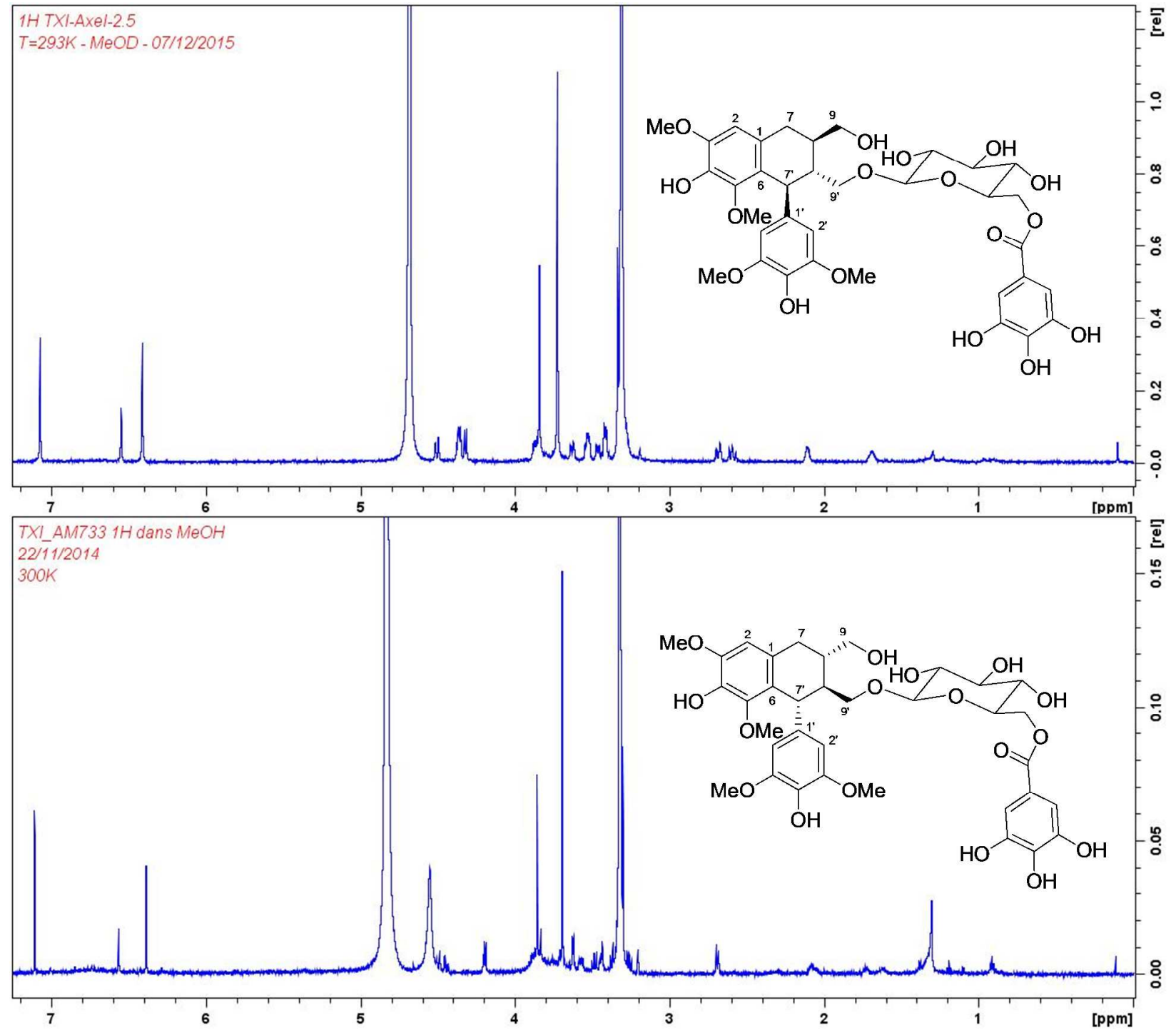


SF. ID COSY $\left(\mathrm{CD}_{3} \mathrm{OD}\right),{ }^{1} \mathrm{H}(600 \mathrm{MHz})$ spectra of the new compounds $\mathbf{1}$ (top) and $\mathbf{2}$ (bottom)

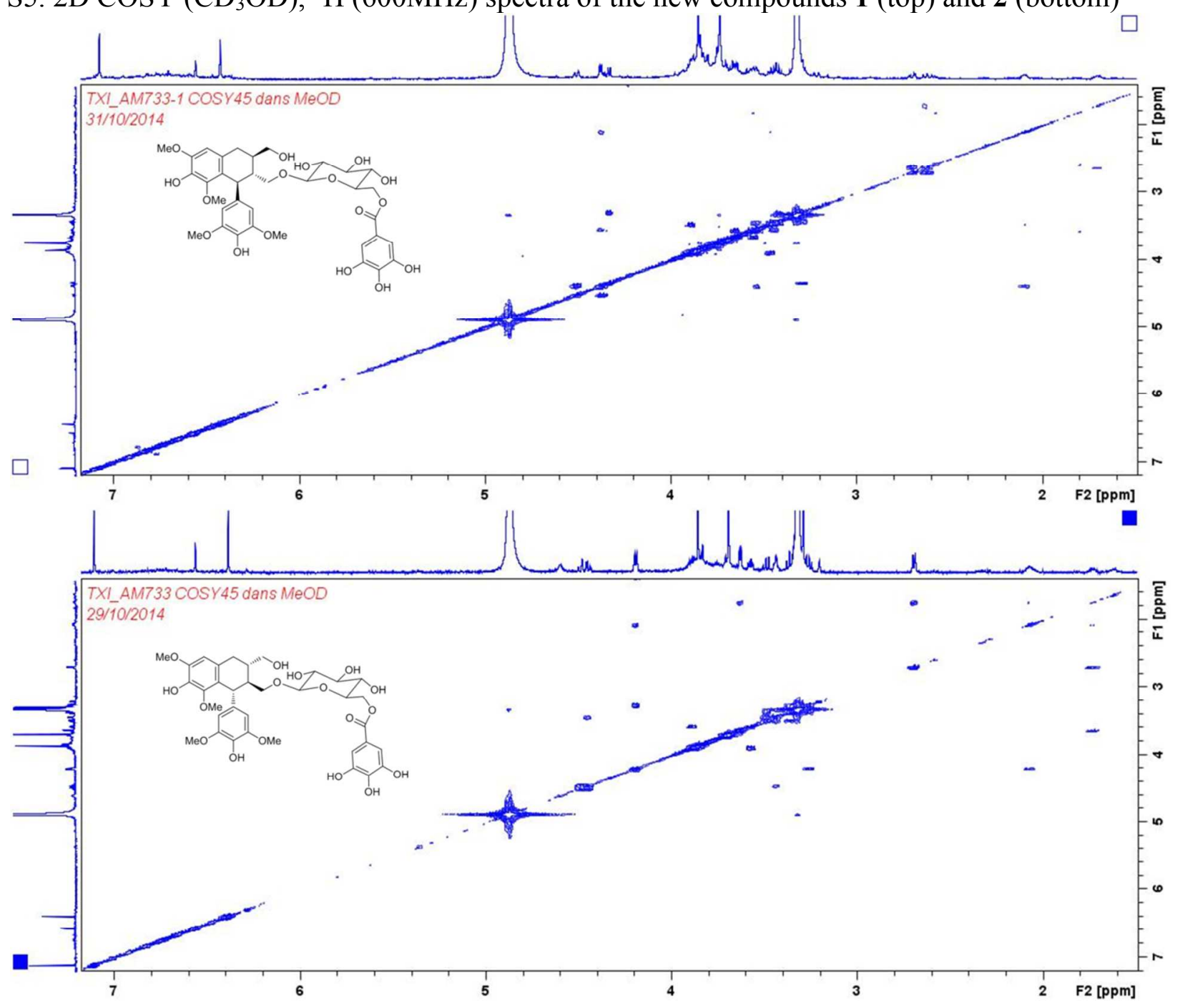


S6. 2D ROESY $\left(\mathrm{CD}_{3} \mathrm{OD}\right),{ }^{1} \mathrm{H}(600 \mathrm{MHz})$ spectra of the new compounds 1 (top) and $\mathbf{2}$ (bottom)
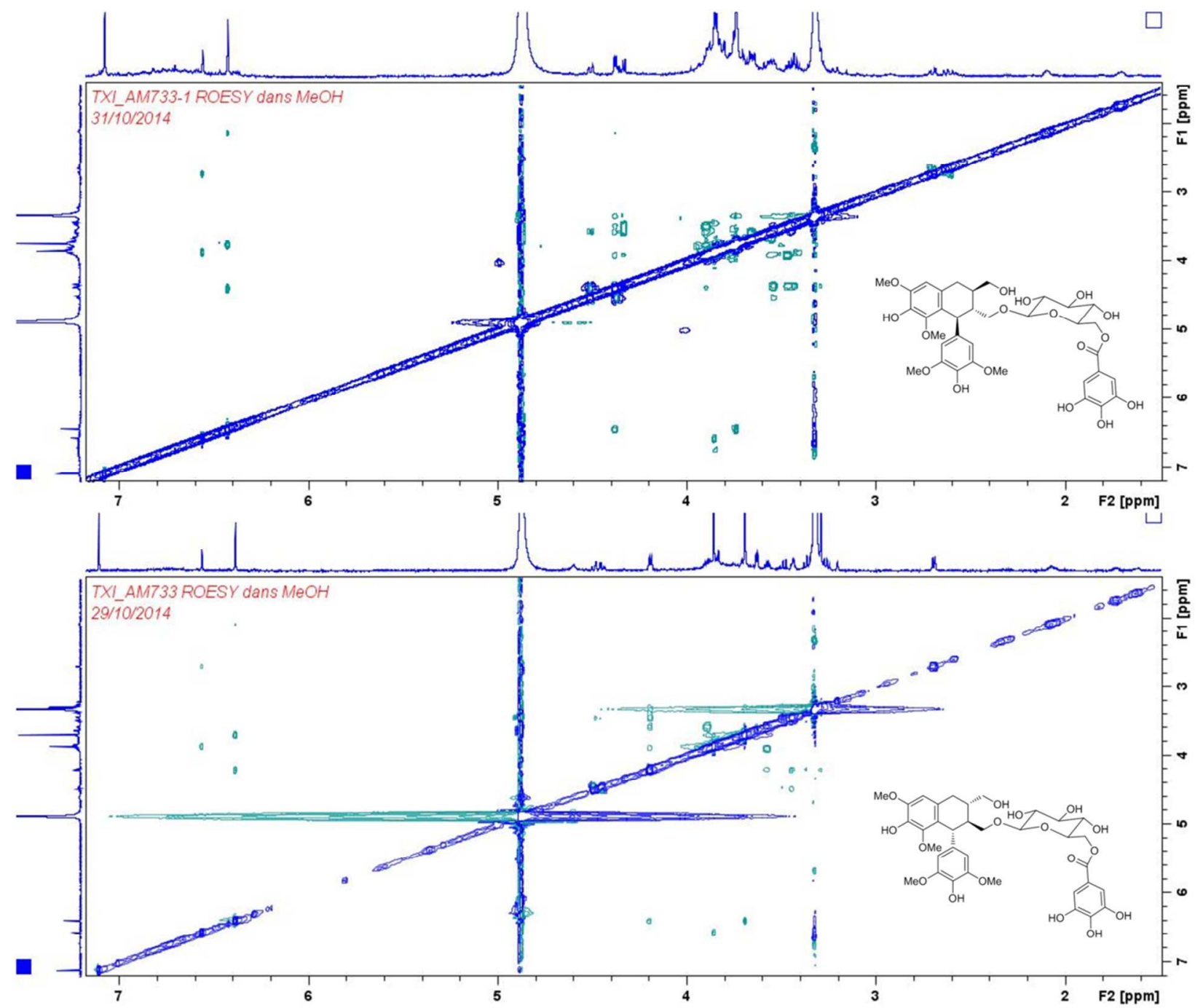
S7. 2D HSQC $\left(\mathrm{CD}_{3} \mathrm{OD}\right),{ }^{1} \mathrm{H}(600 \mathrm{MHz})$ and ${ }^{13} \mathrm{C}(150 \mathrm{MHz})$, spectra of the new compounds 1 (top) and 2 (bottom)

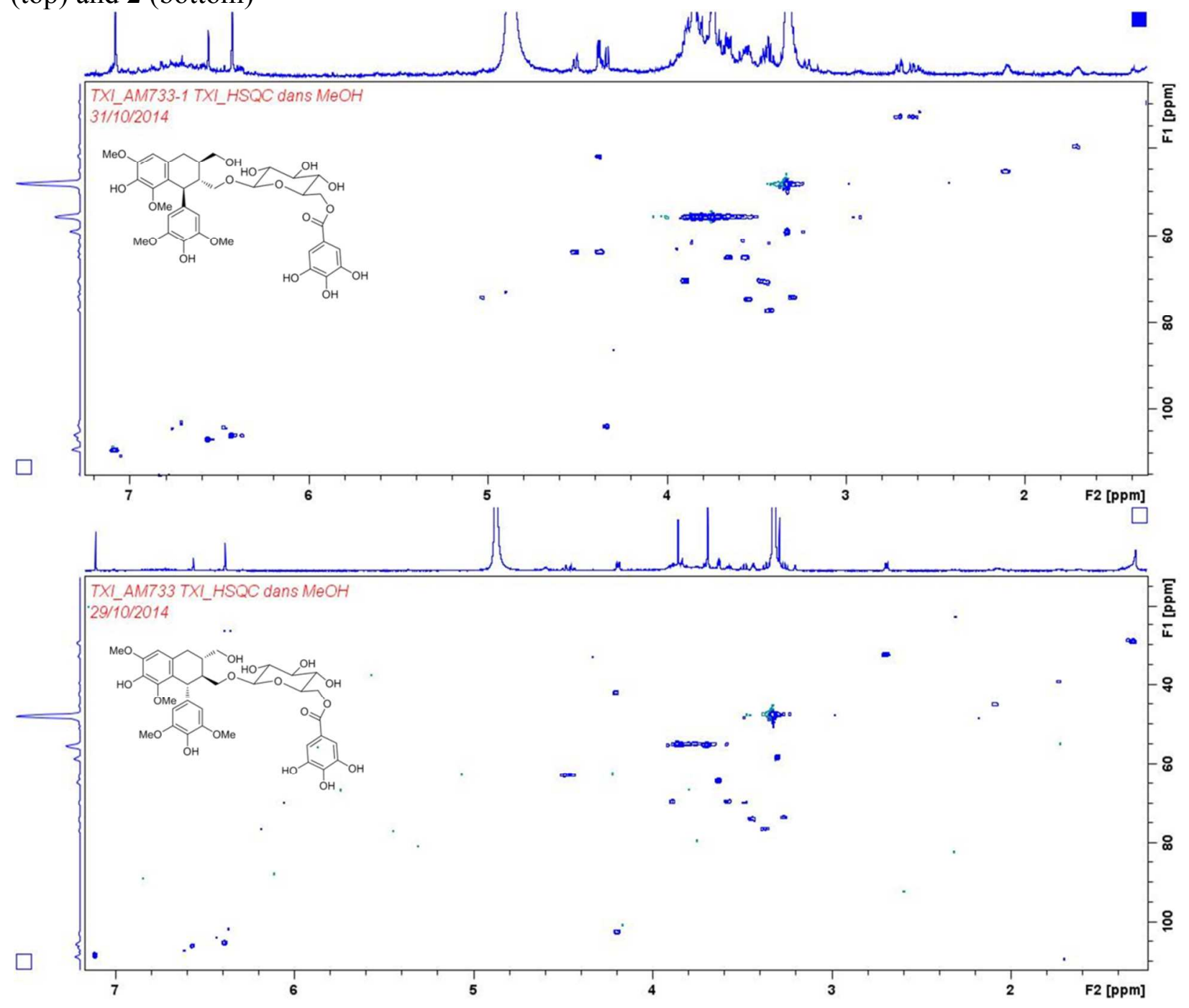


S8. 2D HMBC $\left(\mathrm{CD}_{3} \mathrm{OD}\right),{ }^{1} \mathrm{H}(600 \mathrm{MHz})$ and ${ }^{13} \mathrm{C}(150 \mathrm{MHz})$, spectra of the new compounds 1 (top) and 2 (bottom)

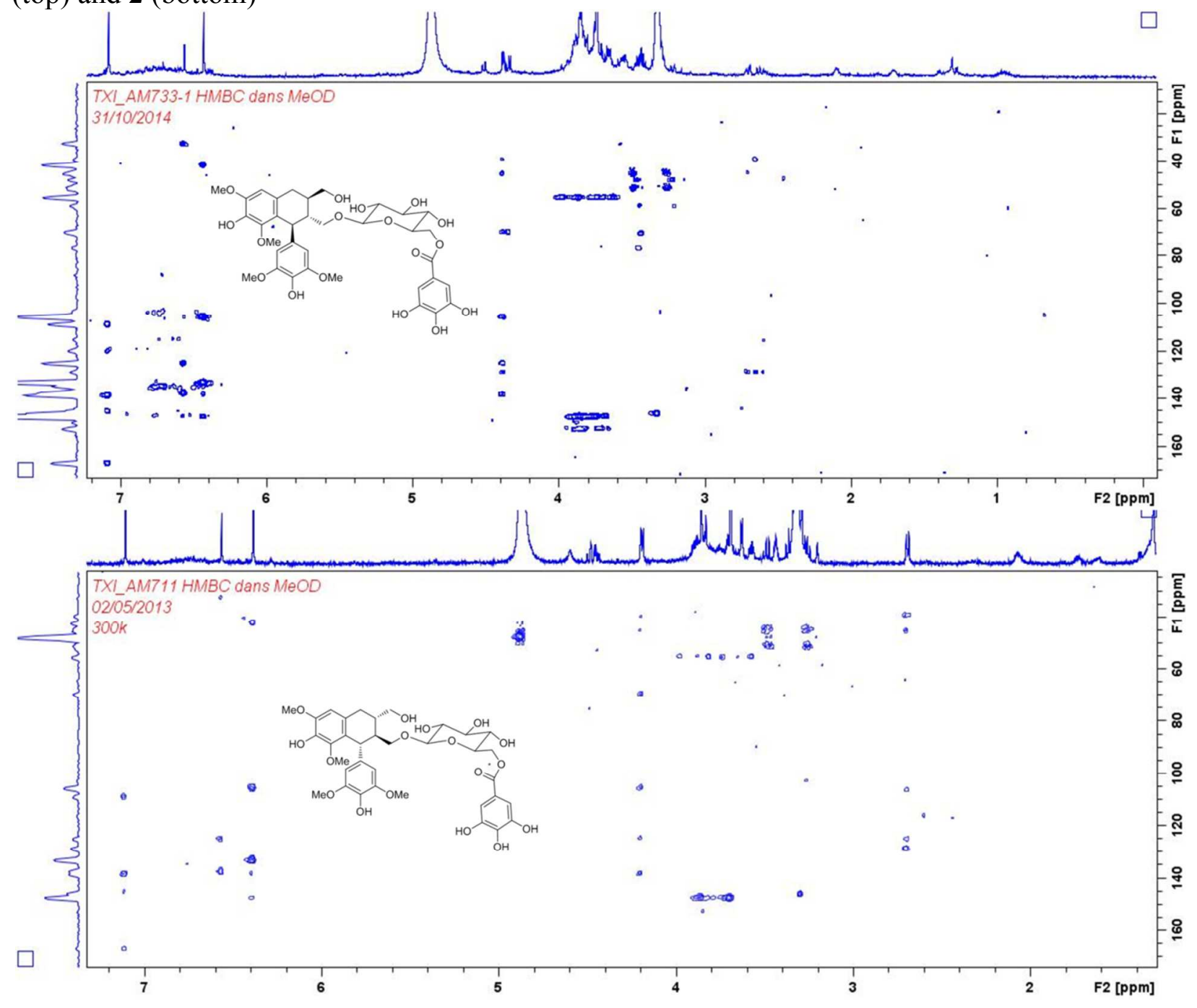

